\title{
Experimental Research on the Mechanical Characteristics and the Failure Mechanism of Coal-Rock Composite under Uniaxial Load
}

\author{
Ke Yang $\left(\mathbb{D},{ }^{1,2}\right.$ Zhen Wei $\left(\mathbb{D},{ }^{1}\right.$ Xiaolou Chi $\mathbb{D},{ }^{1}$ Yonggang Zhang, ${ }^{3}$ Litong Dou, ${ }^{1}$ \\ and Wenjie Liu ${ }^{1}$ \\ ${ }^{1}$ State Key Laboratory of Mining Response and Disaster Prevention and Control in Deep Coal Mines, \\ Anhui University of Science and Technology, Anhui, Huainan 232001, China \\ ${ }^{2}$ Institute of Energy, Hefei Comprehensive National Science Center, Anhui, Hefei, 230031, China \\ ${ }^{3}$ Key Laboratory of Geotechnical and Underground Engineering of Ministry of Education, \\ Department of Geotechnical Engineering, Tongji University, Shanghai 200092, China \\ Correspondence should be addressed to Xiaolou Chi; 2937680510@qq.com
}

Received 14 July 2020; Revised 6 September 2020; Accepted 9 September 2020; Published 19 September 2020

Academic Editor: Fengqiang Gong

Copyright $\odot 2020$ Ke Yang et al. This is an open access article distributed under the Creative Commons Attribution License, which permits unrestricted use, distribution, and reproduction in any medium, provided the original work is properly cited.

\begin{abstract}
Due to the influence of the component structure and combination modes, the mechanical characteristics and failure modes of the coal-rock composite show different characteristics from the monomer. In order to explore the effect of different coal-rock ratios on the deformation and the failure law of the combined sample, the RMT rock mechanics test system and acoustic emission realtime monitoring system are adopted to carry out uniaxial compression tests on coal, sandstone, and three kinds of combined samples. The evolution rules of the mechanical parameters of the combined samples, such as the uniaxial compressive strength, elastic modulus, and Poisson's ratio, are obtained. The expansion and failure deformation characteristics of the combined sample are analyzed. Furthermore, the evolution laws of the fractal and acoustic emission signals are combined to reveal the crack propagation and failure mechanism of the combined samples. The results show that the compressive strength and elastic modulus of the combined sample increase with the decrease of the coal-rock ratios, and Poisson's ratio decreases with the decrease of the coal-rock ratios. The strain softening weakens at the postpeak stage, which shows an apparent brittle failure. The combined sample of coal and sandstone has different degrees of damages under load. The coal is first damaged with a high degree of breakage, with obvious tensile failure. The acoustic emission energy value presents different stage characteristics with increasing load. Crackling sound occurs in the destroy section before the sample reaches the peak, along with small coal block ejection and the partial destruction. The energy value fluctuates violently, with the appearance of several peaks. At the postpeak stage, the coal samples expand rapidly with a loud crackling sound in the destroy section, and the energy value increases dramatically. The crack propagation induces the damage in the sandstone; when the energy reaches the limit value, the instantaneous release of elastic energy leads to the overall structural instability.
\end{abstract}

\section{Introduction}

Most coal seams are interbedded with rock strata [1], as shown in Figure 1. Half coal-rock formation tunnels are widely distributed in underground mines [2], so the stability of coal-rock composite structure is very important to the safety of underground mining. The research discovers that the mining working face will cause the coal damage and the destruction of rock nearby the roof and floor, which will further lead to the occurrence of overall structural instability of coal-rock composite [3-5]. Therefore, the study on the stress characteristics and failure pattern of coal-rock composite is significant to prevent mine disaster.

Recently, an increasing number of scholars have been studying the destruction mechanism and influencing factors of coal-rock composite structures based on experimental and theoretical approach. The experimental research is conducted based on the coal-rock composite with impact propensity, impact damage of electromagnetic radiation, and law of acoustoelectric effect [6-9]. 


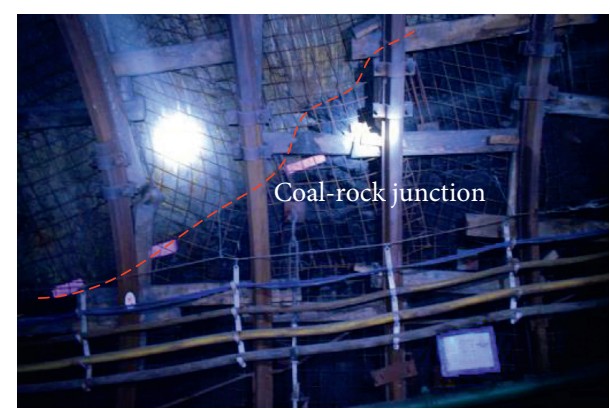

FIGURE 1: Coal-rock interaction interface.

Zhang et al. [10] studied the effects of water influx and loading rate on material properties and crack propagation of coal-rock assemblage. Qiu et al. [12] studied the electromagnetic wave shape and spectral characteristics of coal and rock samples under uniaxial compression. Liu et al. [13] studied mechanical properties and damage constitutive model of coal. Zhang et al. [14] studied the influence of combination method on the mechanical characteristics and destruction characteristics of coalrock composite based on uniaxial and triaxial compression tests. Guo et al. [15] analyzed the strength and macroscopic destruction mechanism of coal-rock composite with different dip angles based on numerical and experimental studies. Tan et al. [16] studied the bursting liability and acoustic emission characteristics of heterogeneous coal and rock mass. Du F [17] studied the unstable failure of gas-bearing coal-rock mass based on physical experiment and numerical simulation. Zhao et al. [18] studied compression-shear strength criterion for a coal-rock assemblage model considering interfacial effects. Li [19] studied deformation and failure characteristics of coal samples under different loading rates. For the problem of rock stability, characteristics of rock damage and gradual failure have also been studied [20-22]. Moreover, Vakili A [23] proposed a new criterion to evaluate the caving property of longwall top coal.

Existing research mainly focuses on the mechanical characteristics and rock burst tendency of the combined sample based on experimental and numerical simulation methods, while the characterization of damage evolution during the loading procedure is analyzed with the help of acoustic and electrical signals. However, there are relatively few studies on the mechanical characteristics and instability mechanism with different coal-rock height ratios. Regarding this, a series of standard samples of pure coal, pure rock, and composite samples with height ratios of $4: 2: 4,3.5: 3: 3.5$, and $3: 4: 3$ have been prepared. The uniaxial compression tests are carried out using the RMT150 testing machine. Meanwhile, the fractal theory is introduced to quantitatively describe the broken form of coal samples, and acoustic emission energy is applied to predict and evaluate the impact risks of coal-rock samples with different height ratios. Generally, this paper can provide a theoretical basis for the prevention of mine engineering disaster and ensure safe and efficient mining process.

\section{Test Overviews}

2.1. Sample Preparation. The coal-rock samples were collected from the lower end of 402102 working face in Hujiahe mine, Shanxi. According to the standard of International Society for Rock Mechanics, the core drilling rig was first used to drill a cylindrical sample with a diameter of $50 \mathrm{~mm}$ $[24,25]$. Then, the stone sawing machine was used to cut the sample to the required height. Then the grinding machine was used to smooth both ends of the sample so that the nonparallelism was not greater than $0.01 \mathrm{~mm}$ and the diameter deviation was not greater than $0.02 \mathrm{~mm}$. To ensure the reliability of the experimental results, a Sonic Viewer-SX ultrasonic system was used to perform $P$-wave tests on rock samples. Then, samples with large dispersion of wave velocity were excluded, while those with similar wave velocities were selected for mechanical tests.

The test samples were divided into 5 groups, where group A was pure rock (sandstone) samples and group B was pure coal samples. Coal-rock composite samples are combined based on the height ratios of (rock : coal : rock) $4: 2: 4$, $3.5: 3: 3.5$, and $3: 4: 3$. Epoxy resin adhesive was used to combine the coal and rock samples into the standard size of $50 \mathrm{~mm} \times 100 \mathrm{~mm}$, which were further divided into groups $\mathrm{C}$, D, and E, respectively, as shown in Figure 2.

2.2. Test Procedure and Plan. The test system is mainly composed of a load control system, an AE monitoring system, and a digital image monitoring system. The RMT$150 \mathrm{~B}$ rock mechanics testing system is used for loading, which can be used for uniaxial compression and triaxial compression tests. In this study, the strain-controlled method with a loading rate of $0.01 \mathrm{~mm} / \mathrm{s}$ was used until specimen fails.

MISTRAS PCI-2 system was adopted to investigate the damage of specimen. Four system AE sensors were glued on the surface of specimens, and Vaseline was used to reduce the difference of acoustic impedance and energy attenuation. The key parameters of the system were calibrated, the sampling frequency is set to $1000 \mathrm{kHz}$, signal gain is set to $40 \mathrm{~dB}$, and in addition, the critical value is set to $40 \mathrm{~dB}$ too.

The loading process was observed by using a Nikond7500 HD camera. It should be noted that radial displacement mentioned in the article was measured in the middle of sample.

\section{Analysis of Test Results}

The synchronous acquisition of test data is accomplished by using a computer. The uniaxial compression stress-strain curves of pure coal and rock samples are shown in Figure 3, and the sample deformation can be divided into four phases [26]. The physical and mechanical parameters of single standard coal and rock samples under uniaxial load are shown in Table 1. It can be seen from Table 1 that the average uniaxial compressive strength, the average elastic modulus, and the average Poisson's ratio of samples in 


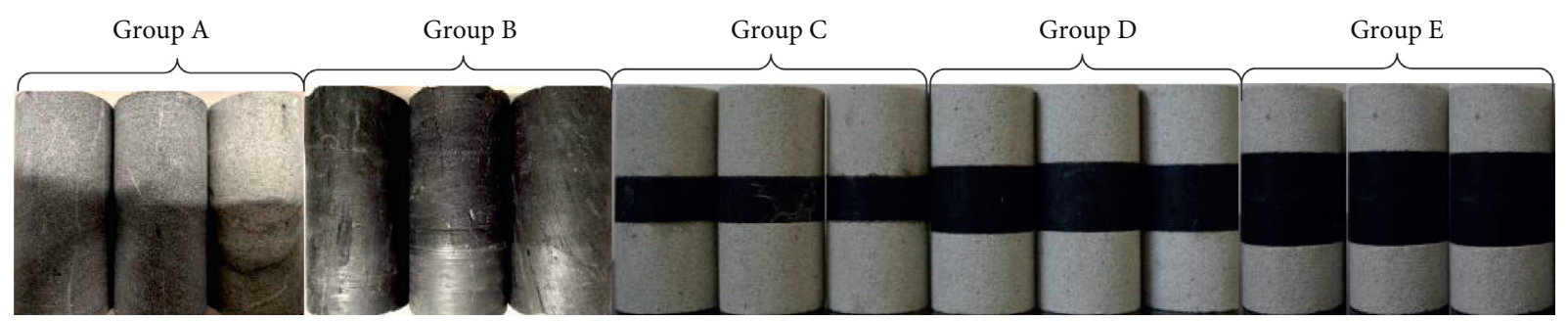

FIGURE 2: Standard coal-rock composite sample.

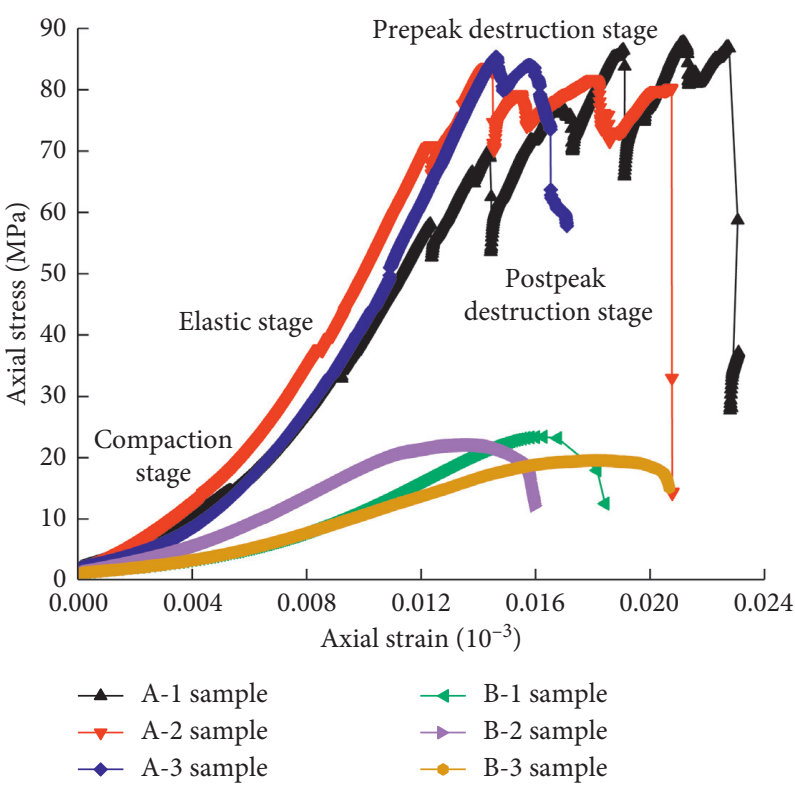

FIGURE 3: Stress-strain curve of single coal and rock sample.

TABLE 1: Physical and mechanical parameters of single coal and rock samples.

\begin{tabular}{lccccc}
\hline Category & Sample number & Size $(\mathrm{mm})$ & Poisson's ratio & Compressive strength $(\mathrm{MPa})$ & Elastic modulus $(\mathrm{GPa})$ \\
\hline \multirow{3}{*}{ Standard rock } & A-1 & $\varphi 50 \times 99.34$ & 0.22 & 78.32 & 9.26 \\
& A-2 & $\varphi 50 \times 100.12$ & 0.24 & 61.86 & 11.24 \\
\hline \multirow{3}{*}{ Standard coal } & A-3 & $\varphi 50 \times 99.86$ & 0.22 & 16.59 & 8.16 \\
& B-1 & $\varphi 50 \times 98.86$ & 0.28 & 21.41 & 1.47 \\
& B-2 & $\varphi 50 \times 99.56$ & 0.29 & 19.48 & 3.23 \\
\hline
\end{tabular}

group $\mathrm{A}$ are $73.61 \mathrm{MPa}, 9.55 \mathrm{GPa}$, and 0.23 , respectively. The average uniaxial compressive strength, the average elastic modulus, and the average Poisson's ratio of samples in group $\mathrm{B}$ are $19.16 \mathrm{MPa}, 2.47 \mathrm{GPa}$, and 0.29 , respectively. Under uniaxial load, the deformation and destruction of samples are closely related to the number of internal microcracks. With more primary cracks, the sample is more likely to fail, and thus the damage intensity is also relatively low. The sample failure is the result of a large number of localized microcracks, the occurrence of which consumes energy directly. When the degree of homogeneity of the sample is lower, its ability to resist deformation is weaker, which produce more localized microcracks and degrade the sample strength [27]. During the test procedure, the rock sample fails rapidly after reaching the peak, which is combined with rock ejection. Most of the ejections are flake and block, with a rapid ejection speed and a violent cracking sound during the whole ejection process. The number of acoustic emissions is much larger in coal samples than that in rock samples during the loading process. And the powder of fragments falls off from the coal sample accompanied by a clear crackle sound when it is close to the peak loading.

3.1. Evolution of Mechanical Characteristics of Coal-Rock Composite. The stress-strain curves of three kinds of composite samples are shown in Figure 4, and it can be seen that the test data of each group is basically consistent. The mechanical parameters of the combined sample in each group are shown in Table 2. It can be seen from Table 2 that the average compressive strength, the average elastic 


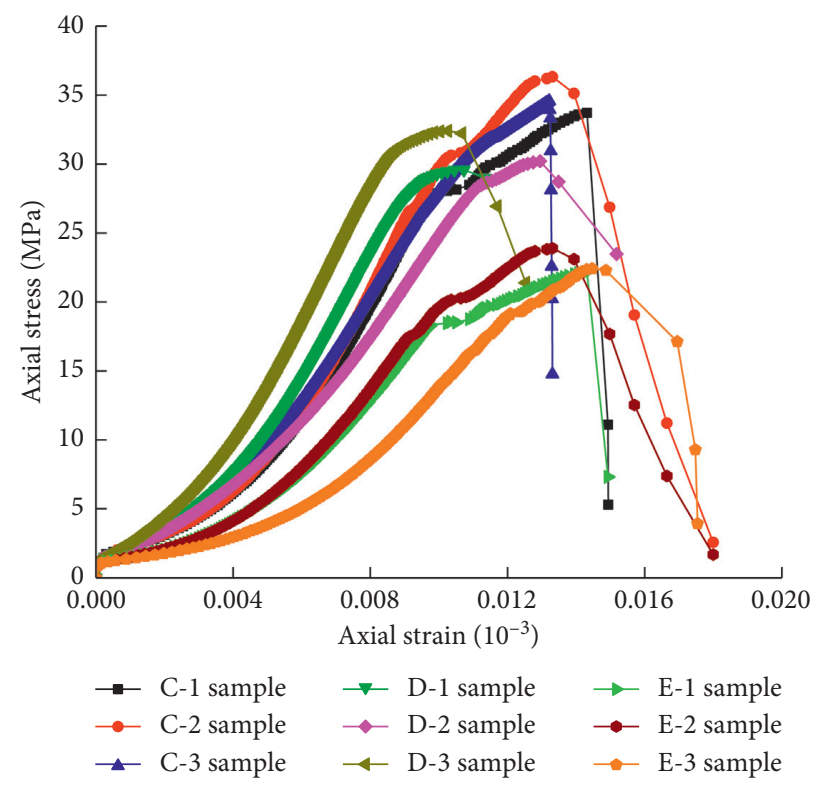

FIgURE 4: Stress-strain curve of the composite.

TABLE 2: Physical and mechanical parameters of the combined sample.

\begin{tabular}{cccccc}
\hline Category & Sample number & Size $(\mathrm{mm})$ & Poisson's ratio & Compressive strength (MPa) & Elastic modulus (GPa) \\
\hline & C-1 & $\varphi 50 \times 99.90$ & 0.24 & 34.67 & 4.86 \\
& C-2 & $\varphi 50 \times 100.27$ & 0.24 & 33.70 & 3.34 \\
Composite samples & C-3 & $\varphi 50 \times 99.64$ & 0.26 & 27.87 & 4.66 \\
& D-1 & $\varphi 50 \times 100.24$ & 0.26 & 28.48 & 3.52 \\
& D-2 & $\varphi 50 \times 99.84$ & 0.26 & 22.04 & 3.69 \\
& D-3 & $\varphi 50 \times 101.16$ & 0.27 & 22.28 & 2.65 \\
& E-1 & $\varphi 50 \times 99.08$ & 0.27 & 18.54 & 3.88 \\
\hline
\end{tabular}

modulus, and the average Poisson's ratio of samples in group $\mathrm{C}$ are $34.90 \mathrm{MPa}, 4.62 \mathrm{GPa}$, and 0.25 , respectively. One sample named C-1 has obvious macroscopic cracks on the surface, which also has a large deviation of the original data. Thus, here is the result of the supplementary test. The average compressive strength, the average elastic modulus, and the average Poisson's ratio of samples in group $\mathrm{D}$ are 29.24 MPa, 3.62 GPa, and 0.26, respectively. And the average compressive strength, the average elastic modulus, and the average Poisson's ratio of samples in group E are 20.95 MPa, $2.92 \mathrm{GPa}$, and 0.28 , respectively. Compared with pure coal sample, the uniaxial compressive strength and elastic modulus of the combined sample increase with the increase of rock proportion but weaken in the strain softening stage. And the stress-strain curve declines rapidly after the peak, which shows brittle failure.

The variation characteristics of the mechanical parameters of pure coal, coal-rock composite, and rock samples with the coal-rock composite proportion are shown in Figure 5. It can be seen from Figure 5 that the average compressive strength of the combined sample in groups C, D, and E increases $82.15 \%, 52.61 \%$, and $9.43 \%$ and the average elastic modulus increases $87.04 \%$, $46.56 \%$, and $18.22 \%$, respectively. It presents that both the bearing capacity and ability to resist deformation have been improved after the coal and rock are combined together. With the increase of the sandstone proportion, its uniaxial compressive strength and elastic modulus both show an increasing trend, and Poisson's ratio shows a decreasing trend. The strength of coal is usually much smaller than that of the rock, and the ability to resist deformation is weaker. The loading process is displacement-controlled, and the deformation of the combined sample is dominated by coal. The coal proportion in group $\mathrm{E}$ is the biggest, and its mechanical characteristics are close to the pure coal sample. The deformation of coal and rock influences each other at the interface of the composite. The coal has experienced a large expansion before the sample reached the peak load. However, the inhibiting effect of the rock leads to additional loading until the sample is damaged, and the overall strength of the rock is improved compared with the pure coal. The ratio of absolute values of radial and axial deformation of samples is Poisson's ratio [28]. The expansion deformation of coal first occurs under external force. Compared with the sample of pure coal, Poisson's ratio of the combined sample is between that of rock and coal due to the inhibition effect of rock. 


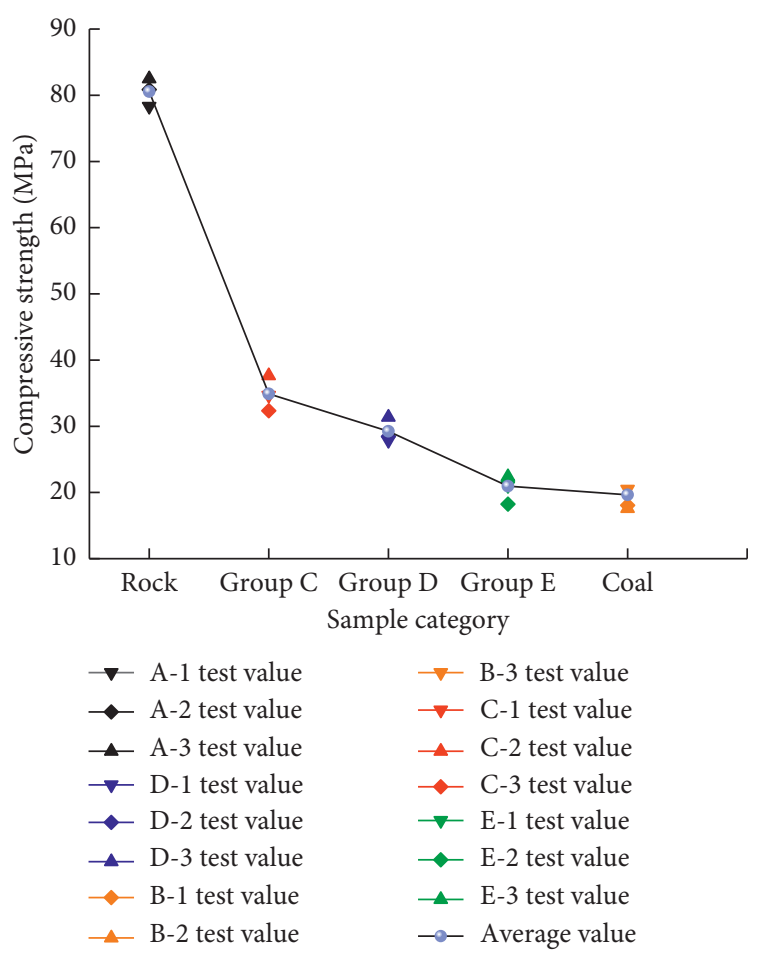

(a)

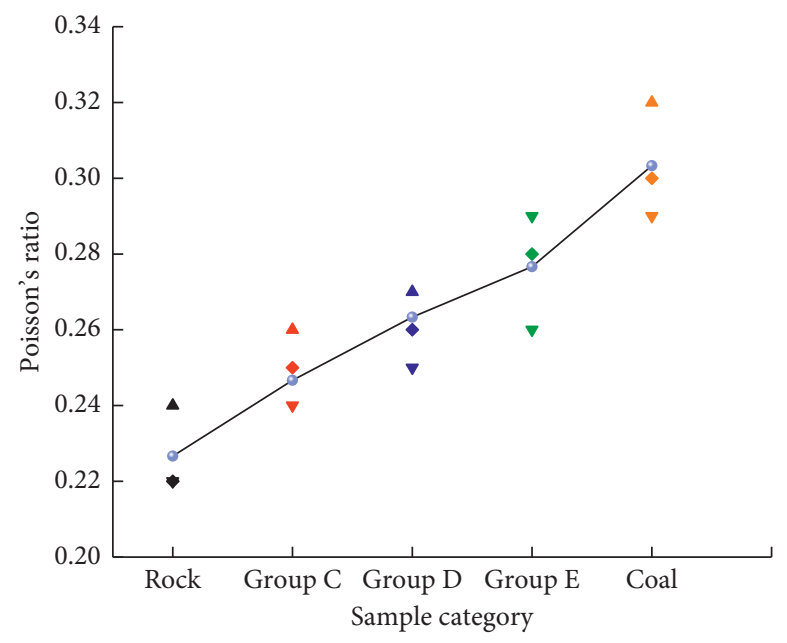

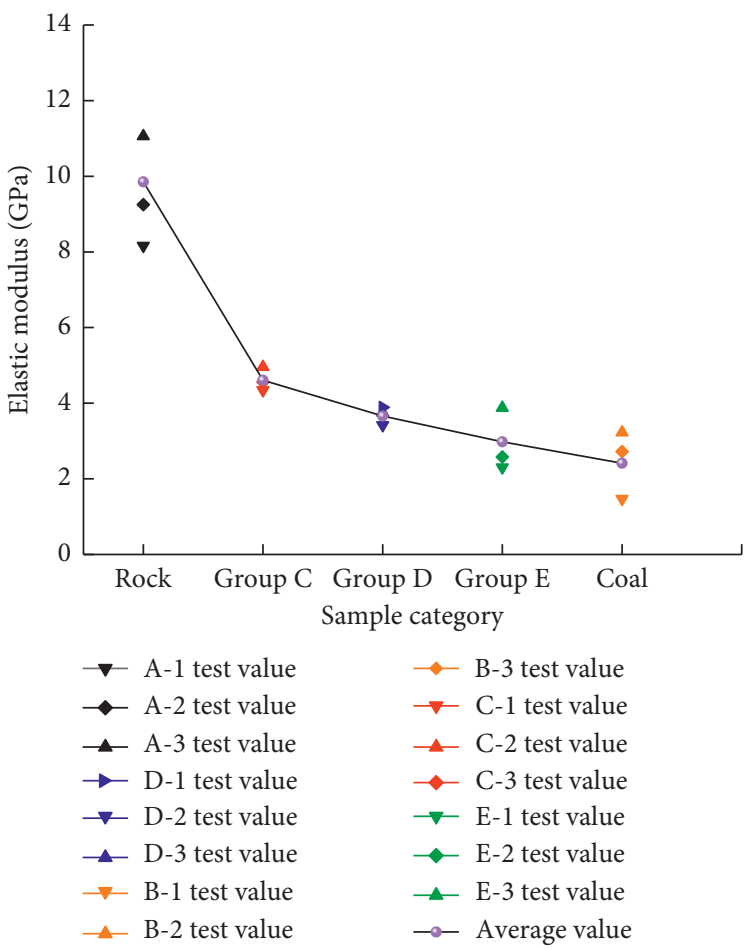

(b)

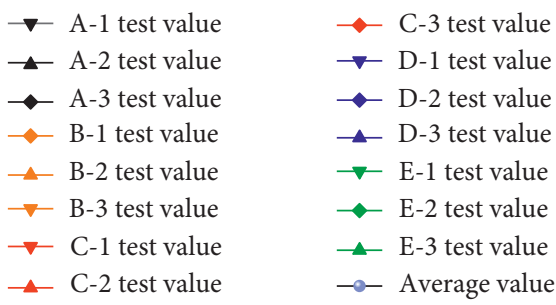

(c)

Figure 5: Test results of mechanical parameters of each group of samples: (a) compressive strength, (b) elastic modulus, and (c) Poisson's ratio.

3.2. Deformation Law and Failure Mode of the Coal-Rock Composite. It can be seen from Figure 6 that three kinds of destroy situation of combined samples can be observed during the procedure of uniaxial compression. Typical failure diagrams are selected. And the failure initiation position, the ejection phenomena, and the acoustic characteristics during destruction are listed in Table 3.

It can be seen from Figure 6 that the coal and rock in combined samples all have different degrees of damage. The coal is mainly damaged in tensile failure, with high degree of 


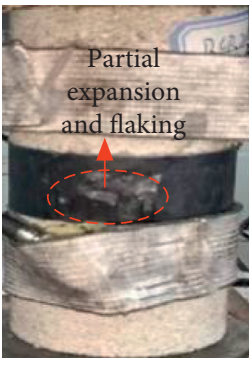

$76 s$

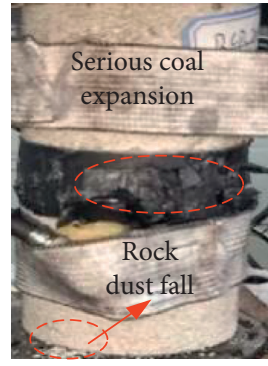

$101 \mathrm{~s}$

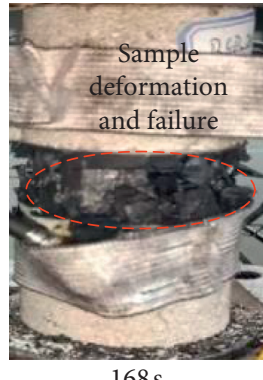

$168 \mathrm{~s}$

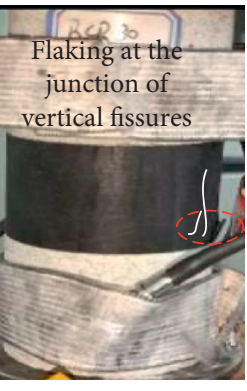

$76 \mathrm{~s}$

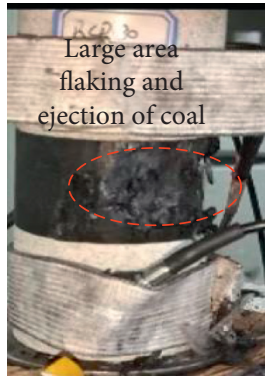

$101 \mathrm{~s}$

(b)

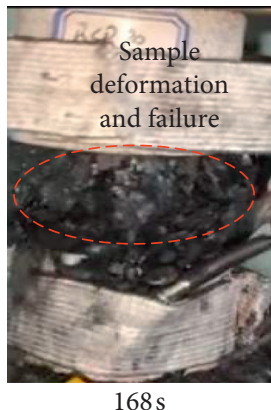

$168 \mathrm{~s}$

(a)

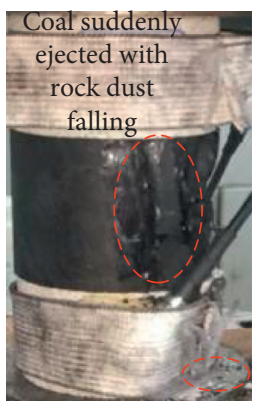

$76 \mathrm{~s}$

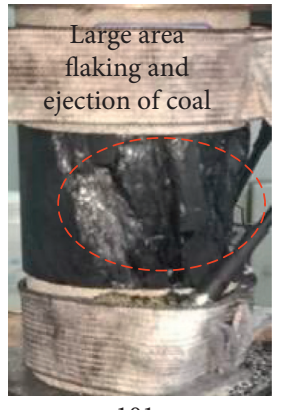

$101 \mathrm{~s}$

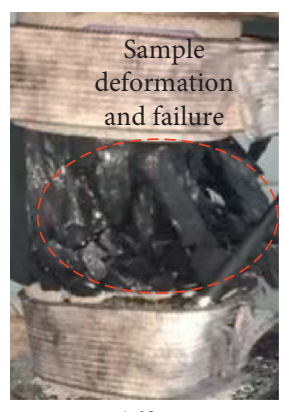

$168 s$

(c)

FIgURE 6: Destruction characteristics of the combined sample. (a) C-1 sample. (b) D-1 sample. (c) E-1 sample.

TABLE 3: Destruction characteristics of combined samples.

\begin{tabular}{|c|c|c|c|c|c|}
\hline $\begin{array}{l}\text { Sample } \\
\text { number }\end{array}$ & $\begin{array}{c}\text { Destructive cracking } \\
\text { location }\end{array}$ & $\begin{array}{c}\text { Acoustic } \\
\text { characteristics }\end{array}$ & Shape & $\begin{array}{l}\text { Ejection } \\
\text { speed }\end{array}$ & Rock dust distribution \\
\hline C-1 & Coal & Slight noise & Fragmented & Faster & Large amount, in equipment head \\
\hline $\mathrm{C}-2$ & Coal & Slight noise & Fragmented & Faster & Large amount, in equipment head \\
\hline C-3 & Coal & Slight noise & Fragmented & Faster & Large amount, in equipment head \\
\hline D-1 & Coal & Crisp noise & Flake and block & Extremely fast & Large amount, in equipment head \\
\hline $\mathrm{D}-2$ & Coal & Crisp noise & Flake and block & Extremely fast & Large amount, in equipment head \\
\hline D-3 & Coal & Crisp noise & Flake and block & Extremely fast & Large amount, in equipment head \\
\hline E-1 & Coal & Burst noise & Flake and block & Extremely fast & $\begin{array}{c}\text { Less amount, inside the device } \\
\text { head }\end{array}$ \\
\hline E-2 & Coal & Burst noise & Flake and block & Extremely fast & $\begin{array}{c}\text { Less amount, inside the device } \\
\text { head }\end{array}$ \\
\hline E-3 & Coal & Burst noise & Flake and block & Extremely fast & $\begin{array}{c}\text { Less amount, inside the device } \\
\text { head }\end{array}$ \\
\hline
\end{tabular}

breakage and uniform distribution of the tensile crack. The rock is relatively complete, with a few nonobvious tensile cracks, which connects to the major failure face of the coal $[29,30]$. Coal in the combined samples is first damaged under uniaxial loading, which causes the occurrence of local stress concentration of the rock. When the coal is further damaged, tensile cracks appear at the same time. The loading process is displacement-controlled, and sample destruction process is recorded with the help of a high definition camera. The destruction degree of coal-rock combined samples is different under the same loading time, but failure initiation positions are all in the coal part. When sample C-1 was loaded to $76 \mathrm{~s}$, the destruction range was small, and localized areas showed dilation and spalling. When it was loaded to $101 \mathrm{~s}$, the coal part of the sample was seriously dilated, and there was rock powder falling on the test bed, but no visible cracks appeared in the sandstone part. When it was loaded to $168 \mathrm{~s}$, the coal part of the sample was fractured, and its bearing capacity was lost. When the D-3 sample was loaded to $76 \mathrm{~s}$, vertical cracks occurred in the coal, and flaky coal was exfoliated at the junction of coal-rock. When it was loaded to $101 \mathrm{~s}$, the coal sample was exfoliated in a large area, accompanied by the phenomenon of ejection. The coal sample was fractured in a wide range when it was loaded to $168 \mathrm{~s}$, accompanied by ringing sound. When sample E-1 was loaded to $76 \mathrm{~s}$, the coal was fractured, the phenomenon of 
ejection appeared, and a small amount of rock powder fell at the junction of coal-rock. The coal sample was ejected in sheets and blocks when it was loaded to $101 \mathrm{~s}$, with a high ejection speed and violent bursting sound. The coal sample was widely fractured when the time was $168 \mathrm{~s}$, and the combined structure lost its bearing capacity.

The statistics about the failure characteristics of samples with different coal-rock height ratios is shown in Table 3. The destruction form of combined samples is analyzed based on the failure initiation position of samples, acoustic characteristics, coal shape, ejection speed, distribution of rock powder, and other aspects. And the results of statistical analysis show that with the increase of coal proportion, the fragmentary coal samples are changed to flake and block, and the sound of acoustic characteristics is changed from slight to popping, which indicates that the degree of damage is decreased.

Even though the strength of the rock is much higher than that of the coal, all rocks have some extents of damage, according to the failure characteristics of composite samples under the condition of uniaxial loading. Coal, as the first failure component of the combined samples, controls the overall strength of combined samples. The rock has been destroyed before reaching its bearing capacity. From the analysis of failure characteristics of some rocks, rock is not always in the elastic state. When the coal cracks spread rapidly and its elastic energy releases suddenly, some rocks also crack at the same time, namely, the damage and failure.

When the axial stress is higher than the crack initiation stress of the composite specimen, crack appears and propagates inside the specimen; however, when the axial stress increases to a certain extent, macrocracks are formed on the surface of the composite samples. Figure 6 shows that the macroscopic failure is induced by the appearance of new crack and extension of primary crack. For composite specimen, initial cracking position often locates in the middle part of coal, while there is no apparent damage in rock part. With the increase of load, a large number of cracks appear at the interface of coal and rock, which easily leads to spalling of coal samples.

The fractal geometry and rock mechanics are combined together in some literatures $[31,32]$, which indicate that the degree of brittleness and fragmentation of rock materials can be quantitatively characterized by fractal dimension. Larger fractal dimension of samples may indicate more broken blocks and smaller volume, which mean a higher degree of breakage.

It is necessary to discuss the fractal dimension characteristics of combined samples and analyze the relationship between different combined samples and the extent of damage. The broken blocks are collected for sieving and weighing after the test is finished, and the fractal dimension of samples is calculated by debris quality-equivalent side length. The calculation formulas are as follows:

$$
\begin{aligned}
& D=1-\alpha, \\
& \alpha=\frac{\lg \left(M_{\mathrm{Leq}} / M\right)}{\lg L_{\mathrm{eq}}},
\end{aligned}
$$

where $D$ is the fractal dimension of broken blocks, $\alpha$ is the slope value of $\left(M_{\mathrm{Leq}} / M-L_{\mathrm{eq}}\right)$ in double logarithmic coordinates, and $\left(M_{\text {Leq }} / M\right)$ is the percentage of debris accumulated with the equivalent side length less than $L_{\text {eq }} \cdot M_{\text {Leq }}$ is corresponding to debris quality when the equivalent side length is $L_{\text {eq }}$, and $M$ is the total debris quality in the calculation scale.

The sieving sizes are 30.0,25.0,20.0,15.0, 10.0, 5.0, and $2.5 \mathrm{~mm}$. The statistical table about the broken blocks' size and quality and fractal dimension of samples in each group are shown in Table 4. It is found that the greater the fractal dimension is, the higher the damage degree will be. The fractal dimension of samples is between 2.11 and 2.39, which is lower than the fractal dimension of sandstone measured in the literature. This indicates the existence of large amount of cracks inside the coal, which make the deformation and destruction more thorough under the effect of external load. The relationship between fractal dimension and coal-rock proportion is shown in Figure 7. It can be seen that the fractal dimension of combined samples decreases with the increase of coal-rock proportion. When the fractal dimension of samples is larger, the size of broken blocks is bigger, with increasing amounts and decreasing size.

\section{Analysis of Acoustic Emission Characteristics of Coal-Rock Composite}

The mechanical characteristics and acoustic emission law of coal-rock composite under uniaxial load are achieved based on tests on the standard combined samples, and stress-strain curves and evolution law of acoustic emission of typical combined samples are shown in Figure 8. It can be seen from Figure 8 that the stress-strain curves of the combined sample under uniaxial compression are divided into four segments, which include compaction segment (initial point to point $a$, concave), elastic segment (point a to point $b$, linear increase), failure segment before peak (point $b$ to point $c$, fluctuated increase), and failure segment after peak (point $c$ to end point, linear decrease). The compaction section of the sample mainly occurred in the closure of the native cracks in the coal and sandstone and the compaction of the coal-rock interface, and the energy value fluctuates slightly. After the compaction segment, samples come into elastic segment (linear and nonlinear), and the energy value is stable. And initiation and propagation of new cracks occur inside the samples during this phase, with a small amount of flake for spallation. Some coal samples have a crackle sound in the destroy segment before peak, with ejection of small coal block and small amount of rock powder falling, and then localized coal samples are destroyed and the energy value fluctuates intensely; thus, a number of peaks occur. A sudden expansion of coal samples occurs in destroy segment after peak, with ejection of small coal block and obvious crackle sound, and the energy value increases suddenly [33].

The compressive strength of the coal sample is 19.48 23.41 MPa, which is about $1 / 5 \sim 1 / 4$ of the strength of sandstone. The sample also has acoustic emission signal under lower load during initial loading because the coal is soft and the cracks are well developed. However, the effect of mutually 
TABLE 4: Distribution statistics of broken pieces after combined sample failure.

\begin{tabular}{|c|c|c|c|c|c|c|c|c|c|c|c|}
\hline \multirow{2}{*}{$\begin{array}{l}\text { Sample } \\
\text { number }\end{array}$} & \multicolumn{7}{|c|}{ Size $(\mathrm{mm})$} & \multirow{2}{*}{$\begin{array}{l}\text { Total quality } \\
(\mathrm{g})\end{array}$} & \multirow{2}{*}{$\begin{array}{c}\text { Fractal } \\
\text { dimension }\end{array}$} & \multirow{2}{*}{$\begin{array}{l}\text { Average } \\
\text { value }\end{array}$} & \multirow{2}{*}{$\begin{array}{c}\text { Damage } \\
\text { form }\end{array}$} \\
\hline & $0 \sim 2.5$ & $2.5 \sim 5$ & $5 \sim 10$ & $10.0 \sim 15$ & $15.0 \sim 20$ & $20.0 \sim 25$ & $25.0 \sim 30$ & & & & \\
\hline C-1 & 7.41 & 3.32 & 4.99 & 6.36 & 8.22 & 20.33 & 0.00 & 50.62 & 2.36 & \multirow[b]{3}{*}{2.35} & \\
\hline $\mathrm{C}-2$ & 6.91 & 5.94 & 11.47 & 8.76 & 13.46 & 0.00 & 0.00 & 46.54 & 2.31 & & \\
\hline $\mathrm{C}-3$ & 7.02 & 2.56 & 6.79 & 5.31 & 10.21 & 0.00 & 22.25 & 54.14 & 2.39 & & \\
\hline D-1 & 11.08 & 8.41 & 6.36 & 12.48 & 15.61 & 28.38 & 0.00 & 82.32 & 2.25 & \multirow{3}{*}{2.28} & \\
\hline $\mathrm{D}-2$ & 9.85 & 5.22 & 8.76 & 10.53 & 16.54 & 27.55 & 0.00 & 78.45 & 2.29 & & \\
\hline D-3 & 11.46 & 6.12 & 11.93 & 11.22 & 14.58 & 0.00 & 23.84 & 79.15 & 2.31 & & \\
\hline E-1 & 14.83 & 6.90 & 13.38 & 9.54 & 10.26 & 18.32 & 36.51 & 109.74 & 2.18 & \multirow{3}{*}{2.17} & \\
\hline E-2 & 9.05 & 5.79 & 6.93 & 8.74 & 11.61. & 0.00 & 54.96 & 97.08 & 2.23 & & \\
\hline E-3 & 7.04 & 11.28 & 10.53 & 7.57 & 4.36 & 19.01 & 29.66 & 90.45 & 2.11 & & \\
\hline
\end{tabular}

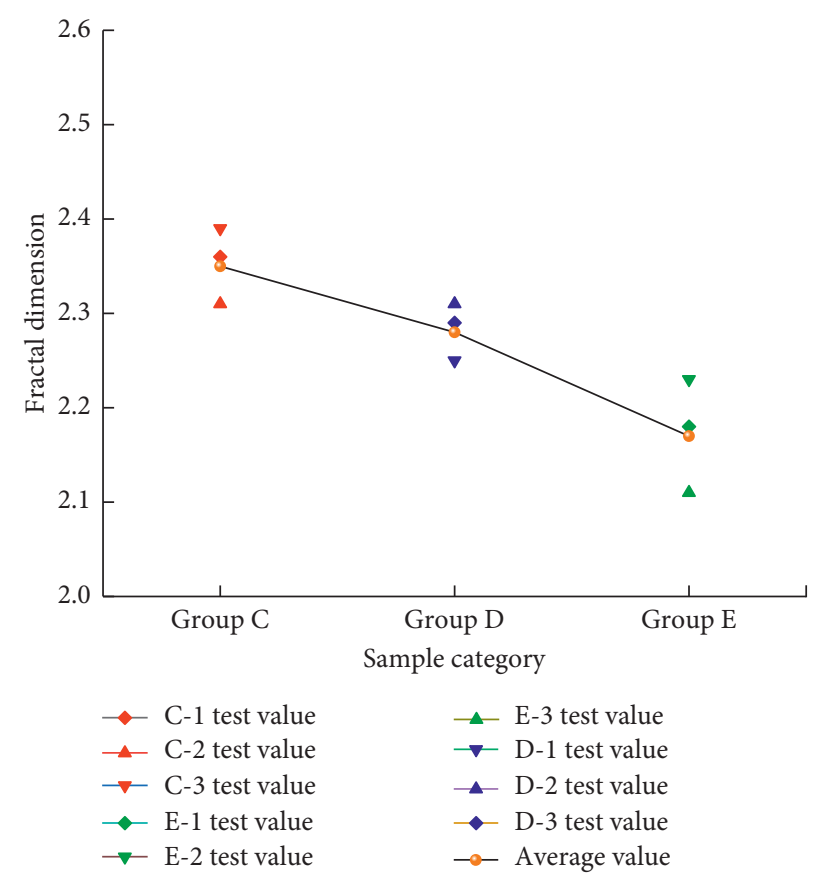

FIgURE 7: Fractal dimension characteristics of the combined samples.

coordinate inhibition exists between sandstone and the coal, which cause the small change of the overall energy value. The effects of mutually coordinate inhibition that exists between sandstone and coal are basically completed with increasing load. The elastic energy of coal is gathered and released, and microcracks at the interface of the sandstone are produced by the instantaneously released elastic energy, which further induces the instability of the combined structure.

\section{Discussion on Instability of the Combined Mechanical Model}

The strength of coal layer is lower than that in most coal stratum, and the rock is in the elastic stage before the external load reaches the ultimate strength of the coal.
Therefore, the sandstone in combined samples can be simplified as a spring-like structure, and a mechanical model of coal-rock composite is constructed, as shown in Figure 9.

If the loaded $P_{1}, P_{2}$ of sandstone in combined samples are in direct proportion to its deformation $x_{1}, x_{2}$, the formula is as follows:

$$
\begin{aligned}
& P_{1}=k_{1} x_{1}, \\
& P_{2}=k_{2} x_{2},
\end{aligned}
$$

where $k_{1}$ and $k_{2}$ are the stiffness of the top and bottom parts of the sandstone, respectively.

In order to study the unstable deformation of combined samples, the time variable $t$ is introduced to establish the functional relationship between coal load and displacement: 


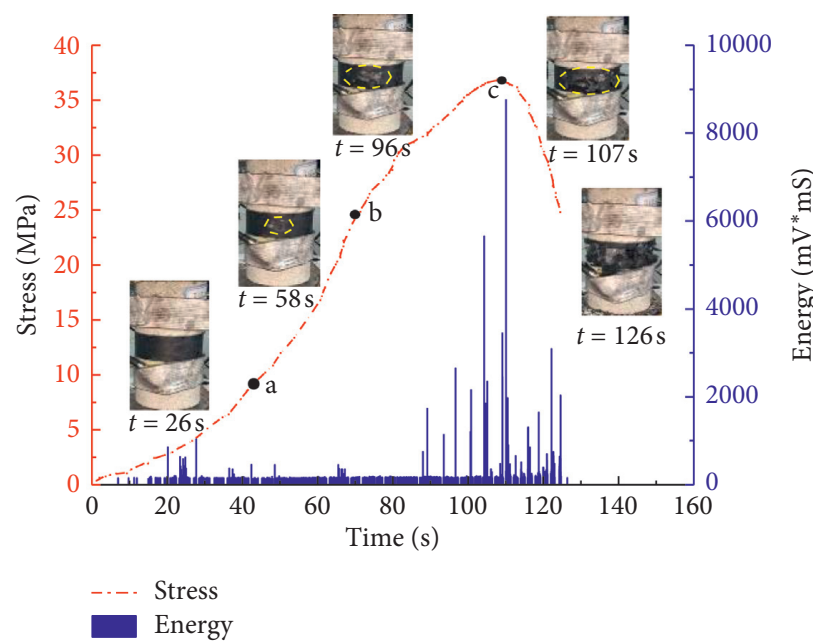

(a)

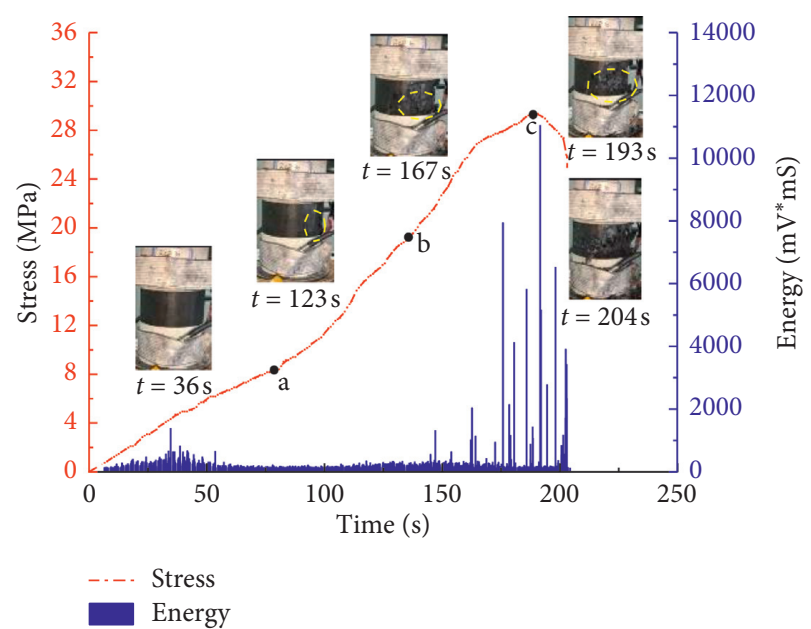

(b)

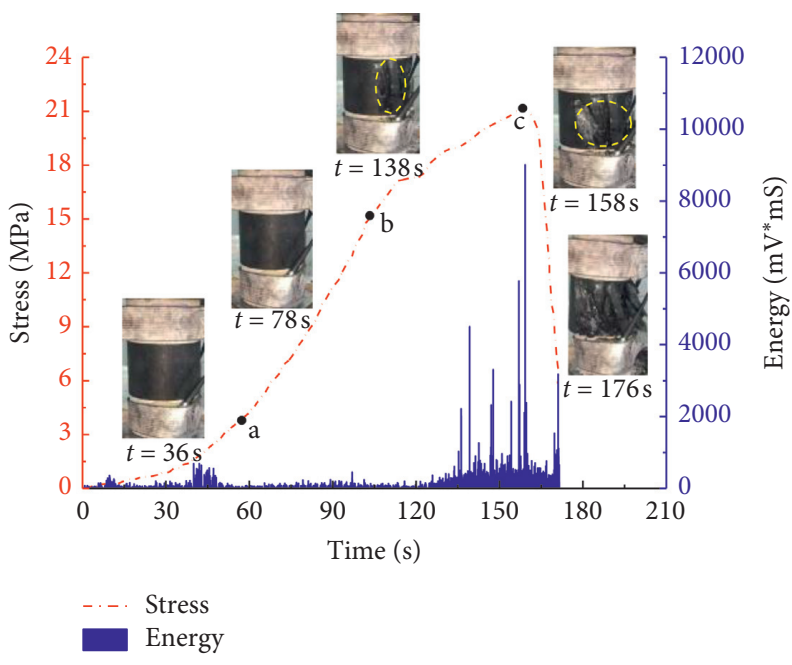

(c)

FIGURE 8: Evolution law of stress-strain and acoustic emission of a typical combined sample: (a) C-1 sample; (b) D-3 sample; (c) E-1 sample.

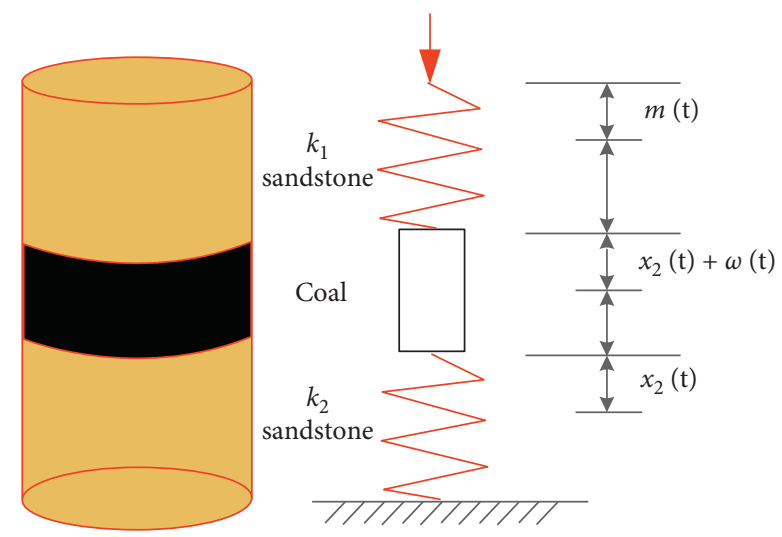

Figure 9: Combined sample mechanical model.

$$
P(t)=f(\omega(t))
$$

where $P(t)$ is the load and $\omega(t)$ is the displacement function under the corresponding load.

The sample gravity is ignored, which obtains the mechanical equilibrium condition of combined samples:

$$
P(t)=P_{1}(t)=P_{2}(t) .
$$

It can be seen from Figure 9 that the total displacement $m(t)$ of the combined samples satisfies the following:

$$
m(t)=x_{1}(t)+\omega(t)+x_{2}(t) .
$$

The rigidity press machine is slowly loaded till samples damage, and the displacement of each part of the combined 
sample changes with time $t$. Substituting (3) (5) into equation (6), then

$$
\frac{f(\omega(t))}{k_{1}}+\omega(t)+\frac{f(\omega(t))}{k_{2}}=m(t) .
$$

Taking the derivative of both sides of the above equation with respect to time, we could obtain the equation of displacement function relationship of combined samples:

$$
\frac{f^{\prime}(\omega(t)) \dot{\omega}}{k_{1}}+\dot{\omega}+\frac{f^{\prime}(\omega(t)) \dot{\omega}}{k_{2}}=\dot{m},
$$

where $f^{\prime}(\omega(t))$ is the tangent slope of coal load-displacement curve, namely, stiffness of the coal. When $f^{\prime}(\omega(t))>0$, $\dot{\omega}<\dot{m}$, the deformation velocity of coal is smaller than the overall deformation velocity in combined samples, and coal samples are in the stable loading stage. When $f^{\prime}(\omega(t))=0$, $\dot{\omega}=\dot{m}$, the displacement of the sandstone at the top and bottom of combined samples reaches the limit, and the coal sample is in the ultimate strength state. When $f^{\prime}(\omega(t))<0$, $\dot{\omega}>\dot{m}$, the deformation velocity of coal is larger than the overall deformation velocity in combined samples, and the coal samples are in the failure unloading stage. Therefore, the instability of combined samples is related to the stiffness of coal and rock, that is, to the mechanical characteristics of coal and rock. When the sample is destroyed, which induces the growth of microcracks in the sandstone, damage and instability will occur after the external load exceeds the strength of system limit.

\section{Conclusions}

The results obtained draw the following conclusions:

(1) The uniaxial compressive strength and elastic modulus of the combined samples are between that of single coal and sandstone samples and are close to the values of pure coal. The effect of coordinate inhibition of coal samples is influenced by sandstone. Compared with single coal, the resistance to deformation of the combined sample is enhanced and its expansion section lasts longer. During the loading process, the coal sample weakens in postpeak strain softening stage and decreases rapidly in the stressstrain curve with the decrease of coal-rock proportion, which shows a strong brittle failure.

(2) The parts of coal and sandstone in the combined sample have different degrees of damages under load. Coal is first damaged with a high degree of breakage, and the main failure mode is the tensile damage. The coal and sandstone continually gathers elastic energy in the compression process of samples, and a large amount of elastic energy is released at the instant of coal sample failure, which results in sandstone damage. The damage extent of samples increases with the decrease of coal-rock proportion.

(3) The fractal dimension is used to describe the failure characteristics of the coal fragments of combined samples and the fractal dimension which is between
2.11 and 2.39, which indicates the existence of large amount of cracks inside the coal. And the deformation and destruction of coal sample are more thorough under the effect of external load. The fractal dimension and damage extent of the sample gradually increase with decrease of coal-rock proportion.

(4) Due to the expansion and penetration of cracks in the coal-rock composite, the coal sample is broken, with localized failure. The interpenetration between the localized destruction eventually leads to the failure and instability of the coal sample. There is no macroscopic crack on the surface of sandstone, and only a large amount of rock powder falls at the common boundary of coal-rock. In view of the deformation and failure characteristics of the combined sample, it is necessary to strengthen the support work of coal far from the interface and avoid the rock destruction caused by the crack propagation of coal.

\section{Data Availability}

The data used for conducting classifications are available from the corresponding author upon request.

\section{Conflicts of Interest}

The authors declare that they have no conflicts of interest.

\section{Acknowledgments}

The authors are grateful for the financial support provided by Key Consulting Project of Chinese Academy of Engineering (2020-XZ-13) and China National Key Research and Development Program (2019YFC1904304).

\section{References}

[1] L.-M. Dou, Z.-L. Mu, Z. L. Li, A.-Y. Cao, and S.-Y. Gong, "Research progress of monitoring, forecasting, and prevention of rockburst in underground coal mining in China," International Journal of Coal Science \& Technology, vol. 1, no. 3, pp. 278-288, 2014.

[2] H. P. Li, F. Gao, and Y. Ju, "Research and development of rock mechanics in deep ground engineering," Chinese Journal of Rock Mechanics and Engineering, vol. 34, no. 11, pp. 21612178, 2015.

[3] S. Song, X. Liu, Y. Tan, D. Fan, Q. Ma, and H. Wang, "Study on failure modes and energy evolution of coal-rock combination under cyclic loading," Shock and Vibration, vol. 2020, Article ID 5731721, 16 pages, 2020.

[4] P. Wang, H. Jia, and P. Zheng, "Sensitivity analysis of bursting liability for different coal-rock combinations based on their inhomogeneous characteristics," Geomatics, Natural Hazards and Risk, vol. 11, no. 1, pp. 149-159, 2020.

[5] G. B. Chen, E. Wang, W. Wang, T. Li, and G. Zhang, "Experimental study on the influence of lithology and rock-coal height ratio on mechanical properties and impact effect of combined body," Energy Sources Part A-Recovery Utilization and Environmental Effects, pp. 1-24, 2019. 
[6] L. M. Dou, J. C. Tian, and C. P. Lu, "Study on electromagnetic radiation law of combined coal rock shock damage," Journal of Rock Mechanics and Engineering, vol. 19, pp. 143-146, 2005.

[7] J. P. Zuo, H. P. Xie, A. M. Wu, and J. F. Liu, "Research on the destruction mechanism and mechanical properties of deep coal and rock monomers and composites," Journal of Rock Mechanics and Engineering, vol. 30, no. 1, pp. 84-92, 2011.

[8] C. P. Lu, L. M. Dou, and X. R. Wu, "Spectral analysis and signal identification of rock mass microseismic monitoring," Journal of Geotechnical Engineering, vol. 26, no. 7, pp. 772775, 2005.

[9] L. M. Dou and X. Q. He, "Research on coal rock shock failure model and acoustic and el-ectric precursor criteria," Journal of China University of Mining and Technology, no. 5, pp. 14-19, 2004.

[10] Y. G. Zhang, Z. Zhang, S. I. Xue, R. J. Wang, and M. Xiao, "Stability analysis of a typical landslide mass in the three gorges reservoir under varying reservoir water levels," Environmental Earth Sciences, vol. 79, no. 1, p. 42, 2020.

[11] J. P. Zuo, Y. Chen, and F. Cui, "Differences in mechanical properties and impact tendency of different coal and rock combinations," Journal of China University of Mining and Technology, vol. 47, no. 1, pp. 81-87, 2018.

[12] L. M. Qiu, D. Z. Song, X. Q. He et al., "Multifractal of electromagnetic waveform and spectrum about coal rock samples subjected to uniaxial compression," Fractals, vol. 28, no. 4, Article ID 2050061, 2020.

[13] X. S. Liu, Y. L. Tan, J. G. Ning, Y. W. Lu, and Q. H. Gu, "Mechanical properties and damage constitutive model of coal in coal-rock combined body," International Journal of Rock Mechanics and Mining Sciences, vol. 110, pp. 140-150, 2018.

[14] Z. T. Zhang, J. F. Liu, and L. Wang, "Experimental study on the influence of combination mode on the mechanical and failure characteristics of coal-rock combination," Journal of China Coal Society, vol. 37, no. 10, pp. 1677-1681, 2012.

[15] D. M. Guo, J. P. Zuo, and Y. Zhang, "Research on strength and failure mechanism of coal and rock masses with different inclination combinations," Rock and Soil Mechanics, vol. 32, no. 5, pp. 1333-1339, 2011.

[16] Y.-L. Tan, W.-Y. Guo, Q.-H. Gu et al., "Research on the rockburst tendency and $\mathrm{AE}$ characteristics of Inhomogeneous coal-rock combination bodies," Shock and Vibration, vol. 2016, Article ID 9271434, 11 pages, 2016.

[17] F. Du and K. Wang, "Unstable failure of gas-bearing coal-rock combination bodies: insights from physical experiments and numerical simulations," Process Safety and Environmental Protection, vol. 129, pp. 264-279, 2019.

[18] Z. Zhao, W. Wang, L. Wang, and C. Dai, "Compression-shear strength criterion of coal-rock combination model considering interface effect," Tunnelling and Underground Space Technology, vol. 47, pp. 193-199, 2015.

[19] H. Li, H. Li, B. Gao, D. Jiang, and J. Feng, "Study of acoustic emission and mechanical characteristics of coal samples under different loading rates," Shock and Vibration, vol. 2015, Article ID 458519, 11 pages, 2015.

[20] S. C. Yuan and J. P. Harrison, "A review of the state of the art in modelling progressive mechanical breakdown and associated fluid flow in intact heterogeneous rocks," International Journal of Rock Mechanics and Mining Sciences, vol. 43, no. 7, pp. 1001-1022, 2006.

[21] I. M. Petukhov and A. M. Linkov, "The theory of post-failure deformations and the problem of stability in rock mechanics,"
International Journal of Rock Mechanics and Mining Sciences \& Geomechanics Abstracts, vol. 16, no. 2, pp. 57-76, 1979.

[22] W. L. Feng, C. S. Qiao, S. J. Niu, Z. Yang, and T. Wang, “An improved nonlinear damage model of rocks considering initial damage and damage evolution," International Journal of Damage Mechanics, vol. 29, no. 7, 2020.

[23] A. Vakili and B. K. Hebblewhite, "A new cavability assessment criterion for longwall top coal caving," International Journal of Rock Mechanics and Mining Sciences, vol. 47, no. 8, pp. 1317-1329, 2010.

[24] R. Ulusay, The ISRM Suggested Methods for Rock Characterization, Testing and Monitoring: 2007-2014, Springer, Berlin, Germany, 2014.

[25] F. Gong, J. Yan, X. Li, and S. Luo, "A peak-strength strain energy storage index for rock burst proneness of rock materials," International Journal of Rock Mechanics and Mining Sciences, vol. 117, pp. 76-89, 2019.

[26] C. Wang, J. Liu, J. Feng, M. Wei, C. Wang, and Y. Jiang, "Effects of gas diffusion from fractures to coal matrix on the evolution of coal strains: experimental observations," International Journal of Coal Geology, vol. 162, pp. 74-84, 2016.

[27] T. Zhao, G. B. Crosta, G. Dattola, and S. Utili, "Dynamic fragmentation of jointed rock blocks during rockslide-avalanches: insights from discrete element analyses," Journal of Geophysical Research: Solid Earth, vol. 123, no. 4, pp. 32503269, 2018.

[28] J. Feng, E. Wang, R. Shen, L. Chen, X. Li, and N. Li, "A source generation model for near-field seismic impact of coal fractures in stress concentration zones," Journal of Geophysics and Engineering, vol. 13, no. 4, pp. 516-525, 2016.

[29] S. Y. Zhu, R. X. Liu, S. J. Zhang, and D. X. Hu, "Characteristics of deformation and failure of deep coal seam floor affected by fully mechanized mining," Geotechnical Testing Journal, vol. 39, no. 1, 2016.

[30] W. B. Guo, H. S. Wang, G. W. Don, L. Li, and Y. G. Huang, "A case study of effective support working resistance and roof support technology in thick seam fully-mechanized face mining with hard roof conditions," Sustainability, vol. 9, no. 6, p. 935, 2017.

[31] F. Q. Gong, H. Ye, and Y. Luo, "The effect of high loading rate on the behaviour and mechanical properties of coal-rock combined body," Shock and Vibration, vol. 2018, Article ID 4374530, 9 pages, 2018.

[32] J. Zuo, Z. Li, S. Zhao, Y. Jiang, H. Liu, and M. Yao, “A study of fractal deep-hole blasting and its induced stress behavior of hard roof strata in bayangaole coal mine, China," Advances in Civil Engineering, vol. 2019, Article ID 9504101, 14 pages, 2019.

[33] X. Zhang, B. Ghabraie, G. Ren, and M. Tu, "Strata movement and fracture propagation characteristics due to sequential extraction of multiseam longwall panels," Advances in Civil Engineering, vol. 2018, Article ID 4802075, 17 pages, 2018. 